Vol. 2, No. 1, Juni 2018, Hal. 19-28

e-ISSN 2614-5758 | p-ISSN 2598-8158

crossref: https://doi.org/10.31764/imm.v2i1.1333

\title{
KONSTRUKSI JIWA KEWIRAUSAHAAN MELALUI PELATIHAN STARTUP DIGITAL 4.0 BAGI SISWA SMA
}

\author{
Mohammad Bhanu Setyawan ${ }^{1^{*}}$, Aslan Alwi ${ }^{2}$, Munirah $^{3}$ \\ ${ }^{1,2,3}$ Program Studi Informatika, Universitas Muhammadiyah Ponorogo, Indonesia \\ m.banu@umpo.ac.id
}

\begin{abstract}
ABSTRAK
Abstrak: Pengguna internet aktif di Indonesia sebanyak 90 juta, dan $50 \%$ lebih adalah pengguna dari kalangan anak muda atau yang biasa disebut sebagai generasi digital native. Mereka adalah generasi yang sebenarnya punya kemampuan dan kreatifitas untuk dilibatkan dalam menyelesaikan masalah yang dihadapi masyarakat di era industri 4.0. Namun kurangnya informasi, pengalaman dan bimbingan yang membuat mereka bingung harus bertindak seperti apa. Maka dibutuhkan pelibatan pemangku kepentingan seperti institusi pendidikan untuk membimbing dan mewadahi potensi yang dimiliki oleh generasi sekarang. Salah satu upaya adalah menerapakan kurikulum berbasis kewirausahaan ke dalam sistem pengajaran di sekolah dengan harapan siswa siap mempunyai kemampuan untuk membuat lapangan pekerjaan sendiri. SMA Negeri Sambit Kab. Ponorogo merupakan sekolah yang menerapkan kurikulum kewirausahaan ke dalam mata pelajaran prakarya dan kewirausahaan. Pembaruan materi prakarya dan kewirausahaan perlu dilakukan di era digital saat ini demi mengikuti perkembangan jaman karena itu diperlukan sekali pembekalan kepada siswa bagaiman membangun startup digital yang bisa menjadi alternatif kemampuan yang bisa dimiliki siswa ketika masuk kedalam industri 4.0.
\end{abstract}

Kata Kunci: Wirausaha, Startup digital, Industri 4.0.

\begin{abstract}
Active internet users in Indonesia as many as 90 million, and 50\% more are users of young people or commonly referred to as the native digital generation. They are the generation that actually has the ability and creativity to be involved in solving problems faced by people in the industrial era 4.0. But the lack of information, experience and guidance that makes them confused what to do. Then it takes the involvement of stakeholders such as educational institutions to guide and accommodate the potential of the current generation. One effort is to apply the entrepreneurshipbased curriculum into the teaching system in schools with the hope that students are ready to have the ability to create their own jobs. SMA Negri Sambit Regency Ponorogo is a school that implements entrepreneurship curriculum in the subjects of craftsmanship and entrepreneurship. Renewal of craft and entrepreneurial material needs to be done in the current digital era in order to keep up with the times because it is absolutely necessary to equip students how to build a digital startup that can be an alternative ability that students can have when entering industry 4.0.
\end{abstract}

Keywords: Entrepreneurial, Digital Startup, Industrial 4.0.

\section{A. LATAR BELAKANG}

Indonesia adalah negera yang punya sejuta peluang dan potensi, namun dibalik itu masih banyak masalah yang harus segera diselesaikan. Masalah terbesar adalah populasi penduduk sebesar 255 juta dengan pengguna aktif 
internet sebanyak 95,2 juta (Cobantoro, 2017, 2018). Lebih kurang 50\% total pengguna internet adalah anak muda yang nota bene disebut sebagai generasi digital native yaitu sebuah generasi yang telah akrab dengan dunia digital (Supratman, 2018). Anak muda sekarang sebenarnya punya keahlian dan memiliki pola pikir yang benar sehingga bisa dilibatkan dan menjadi motor penggerak untuk menyelesaikan masalah tersebut (Digital, 2016), (Masykur et al., 2016). Sayangnya mereka bingung harus bagaimana untuk memulai karena minimnya pengetahuan, jaringan dan pengalaman yang dimiliki.

Untuk mewadahi potensi anak muda maka perlu melibatkan pemangku kepentingan untuk memberikan panduan, arahan ataupun petunjuk agar mereka bisa terjun langsung ke hadapan masyarakat dan bisa memberikan dampak positif. Kecakapan menganalisa sebuah permasalahan dengan kreatifitas berbasis nilai ekonomi dengan menggunakan teknologi dapat didorong melalui pembangunan karakter wirausaha digital atau dalam istilah generasi millenial adalah start-up digital (Yohanna \& Wijono, 2016). Salah satu upaya menanamkan karakter wirausaha adalah dengan pembekalan karakter wirasusaha dan softskill pemasaran yaitu dimulai dalam lingkungan Pendidikan melalui program praktikum atau workshop usaha dalam melengkapi kurikulum kewirausahaan (Ratna Wijayanti, Sutikno, \& Sukarnati, 2016).

SMA Negeri 1 Sambit merupakan salah satu sekolah yang juga menerapakan karakter kewirausahaan dalam kurikulumnya dengan memberikan pelajaran kejuruan produk kreatif dan kewirausahaan. Ada beberapa kendala ketika ingin memadukan pelajaran kewirausahaan konvensional yang selama ini sudah diterapkan dan harus bertransformasi menjadi bentuk kewirausahaan digital (startup digital). Kendala tersebut antara lain terbatasnya atau ketidak tahuan pengajar dan siswa bagaimana membuat sebuah startup digital dikarenakan minimnya pelatihan bagi instruktur atau siswanya. Sebenarnya banyak pelatihan tentang startup digital, namun lebih banyak terkonsentrasi di kota-kota besar seperti Jakarta, Bandung dan Surabaya. Jarak yang jauh dan terbatasnya waktu menjadi kendala bagi siswa SMA Negeri 1 Sambit untuk menghadiri acara tersebut.

Perlu adanya kesadaran juga bagi para pelaku startup digital yang sudah mempunyai pengalaman agar mau turun ke sekolah-sekolah terpencil untuk membagikan pengalamanya agar mindset untuk berwirausaha di kalangan anak muda terutama siswa SMA ketika lulus untuk berwirausaha digital. Selain itu untuk mendukung visi pemerintah menjadikan di tahun 2020 menjadikan Indonesia "The Energy Digital of Asia" (Ameliah et al., 2018). Diharapkan dengan pelatihan yang diberikan kepada siswa SMA bisa mencetak pelaku-pelaku startup digital yang bisa membuat lapangan kerja baru dan bermanfaat bagi kemajuan perekonomian Indonesia. 


\section{B. METODE PELAKSANAAN}

\section{Kondisi Mitra}

SMA Negri 1 Sambit Sambit berdiri tahun 1980 yang berlokasi di Jalan Raya Ponorogo - Trenggalek, Kec. Sambit, Kabupaten Ponorogo. SMA Negeri Sambit mempunyai siswa sebanyak 400 dengan pendukung tenaga pengajar sebanyak 35 dan jumlah rombel 15. Salah satu visi dan misi SMA Negeri Sambit adalah memberikan komptensi keahlian di bidang keterampilan dan kewirausahaan agar bisa bersaing dan juga mampu berwirausaha dalam kurikulum pengajarannya.

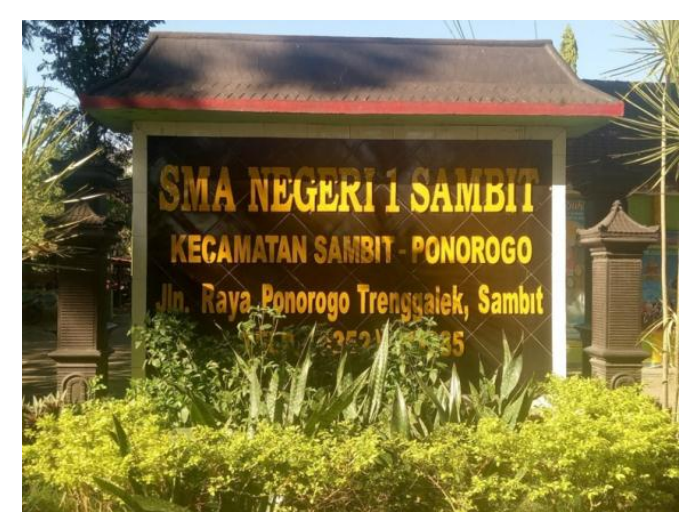

Gambar 1. SMAN 1 Sambit Ponorogo

Kendala yang dihadapi oleh mitra ini adalah rendahnya minat siswa berwirausaha setelah lulus dari sekolah, sebagian besar lulusan mencari pekerjaan seadanya atau meneruskan kuliah bagi keluarga yang mampu, padahal lapangan pekerjaan sangat terbatas. Memasuki industri 4.0 penggunaan teknologi Big Data, IoT, Cloud, Machine Learning dan virtualisasi adalah kemampuan yang harus dimiliki anak didik agar bisa bertahan di industri 4.0. Banyak peluang atau pekerjaan baru yang bisa di dibuat di industri 4.0, salah satunya adalah peluang untuk membuat startup digital. Minimnya pengetahun dan pengalaman membuat startup digital baik dari siswa dan tenaga pengajar menjadi kendala bagi SMA Negeri 1 Sambit untuk menerapkan kewirausahaan 4.0 di sistem pengajaran.

Solusi yang bisa diberikan dari permasalahan yang dialami oleh mitra dengan cara Memberi pelatihan kepada mitra yang meliputi pelatihan bagaimana membangun startup digital 4.0 dari penggalian ide bisnis, memahami struktur organisasi, pitching, membuat strategi pemasaran, membuat prototype sebuah produk dan mengevaluasi keberlanjutan bisnis terutama di industri 4.0.

\section{Prosedur Pelaksanaan}

Pelaksanaan program ini dilaksanan setelah semua perijinan dan persiapan peralatan selesai dilakukan. Kegiatan akan dilakukan di SMAN Sambit Kabupaten Ponorogo. Dalam pelaksanaannya peserta pelatihan akan terdiri dari 40 siswa dari berbagai jurusan yang ada di SMAN Sambit. Pelatihan ini akan dilaksanakan selama satu hari dengan di bagi menjadi enam sesi. Tahapan dalam pelatihan startup digital bisa dilihat pada Gambar 2. 


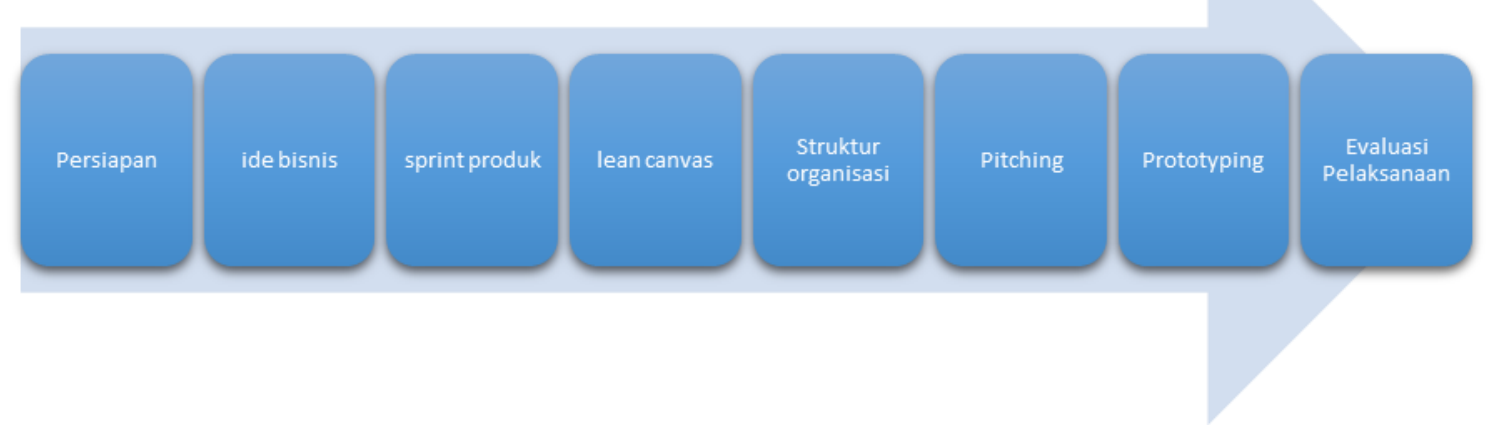

Gambar 2. Metode Pelaksanaan Kegiatan

a. Persiapan

Pada tahap ini mempersiapakan segala kebutuhan yang dibutuhkan sebelum melaksanakan pelatihan seperti MOU, tempat dan jadwal pelatihan dan kriteria peserta yang akan diikutkan dalam pelatihan starup digital.

b. Ide Bisnis

Tahap ini siswa akan dilatih untuk mencari ide-ide unik yang difokuskan bagaimana melihat masalah yang dirasakan masyarakat atau lingkungan sekitar, dari masalah tesrsebut siswa di arahkan untuk mencari solusinya dengan bantuan teknologi 4.0.

c. Sprint Produk

Peserta akan diberikan kemampuan bagaimana produk yang akan diwujudakan layak apa tidaknya dari sisi bisnis.

d. Lean Canvas

Peserta akan diajari bagaimana membuat peta konsep usaha yang akan dibangun dengan mengisi model bisnis lean canvas yang memudahkan calon pengusaha untuk mendapat gambaran umum tentang usahanya kelak.

e. Struktur Organisasi

Pada bagian ini peserta minimal akan diajarkan bagaimana membentuk sebuah teamwork yang mempunyai fungsi dan tugas masing-masing sesai dengan perannya. Misal saat akan membuat startup struktur organisasi apa yang akan dibuat seperti menunjuk Chief Executive Officer, Chief Technical Officer, Chief Financial Officer.

\section{f. Pitching}

Pada bagian ini peserta dilatih untuk presentasi di depan investor untuk menjelaskan secara singkat tentang produk inovasi yang akan dibuat.

\section{g. Prototyping}

Peserta akan dilatih bagaimana menyipakan profil bisnis dan produk, memanfaatkan fitur google maps, menggunakan fitur 
pengiklan di facebook dan instagram, membuat website atau blog dan mendesain interface aplikasi menggunakan marvel

h. Evaluasi Pelaksanaan

Untuk mengetahui bahwa pengabdian ini sesuai dengan harapan peserta dan tim pengabdi, maka Hasil evaluasi pelaksanaan pengabdian akan disajikan berupa tabel data yang diperoleh dari hasil pengisian responden terhadap kuesioner yang diberikan. Pada kuesioner ini yang dijadikan target adalah peserta. Jumlah responden sebanyak 40 peserta. Dalam penghitungan hasil kuesioner yang didapat, penulis melakukan penghitungan metode Skala Likert.

\section{HASIL DAN PEMBAHASAN}

Kegiatan dilaksanakan di sekolah SMAN 1 Sambit Ponorogo dengan dihadiri oleh 40 siswa. Pelatihan dilaksanakan pada tanggal 07 September 2019. Durasi pelatihan membutuhkan waktu 8 jam efektif yang diselenggarakan selama satu hari. Berikut penjelasan proses kegiatan pengabdian yang sudah di lakukan:

\section{Persiapan}

Pada tahap ini melakukan kerja sama dan pembuatan MOU dengan pihak SMAN 1 Sambit, dalam hal ini diwakili oleh Kepala Sekolah dengan tim pengabdi Universitas Muhammadiyah Ponorogo. Adapun topik pelatihan yang diberikan pada sesi pertama adalah pengenalan teknologi revolusi industri 4.0 yang akan diahadapi oleh siswa. Berikut contoh materi yang akan di berikan: materi tentang konsep revolusi industri 4.0, wawasan tentang apa itu startup dan model startup yang sekarang berkembang.

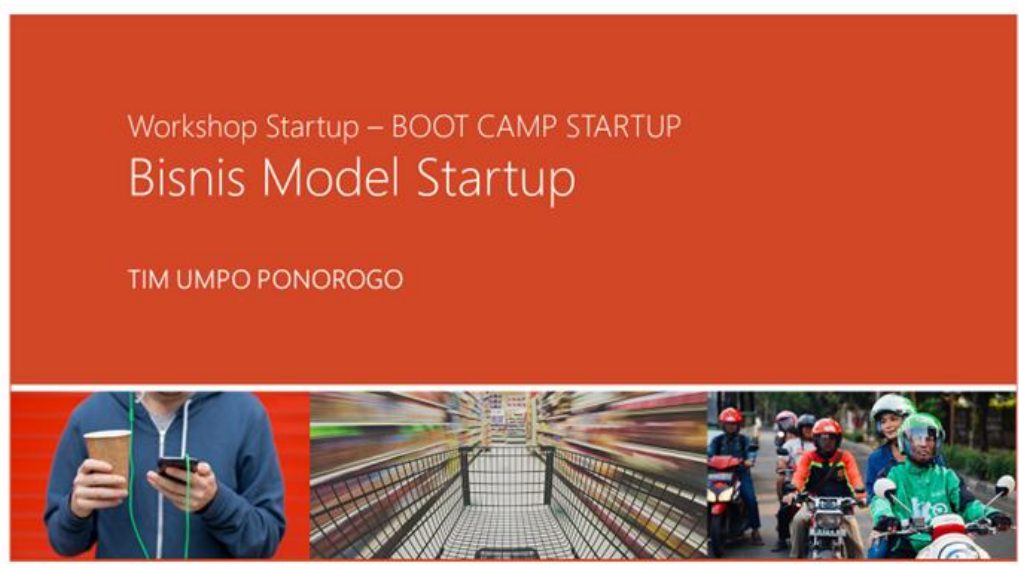

\section{Ide Bisnis}

Gambar 3. Model Startup Di Indonesia

Pada sesi ini setiap kelompok di haruskan untuk memunculkan ide bisnis berbasis digital apa yang akan mereka buat untuk mengatasai atau memecahkan permasalahan yang terjadi di lingkungan sekitar. 


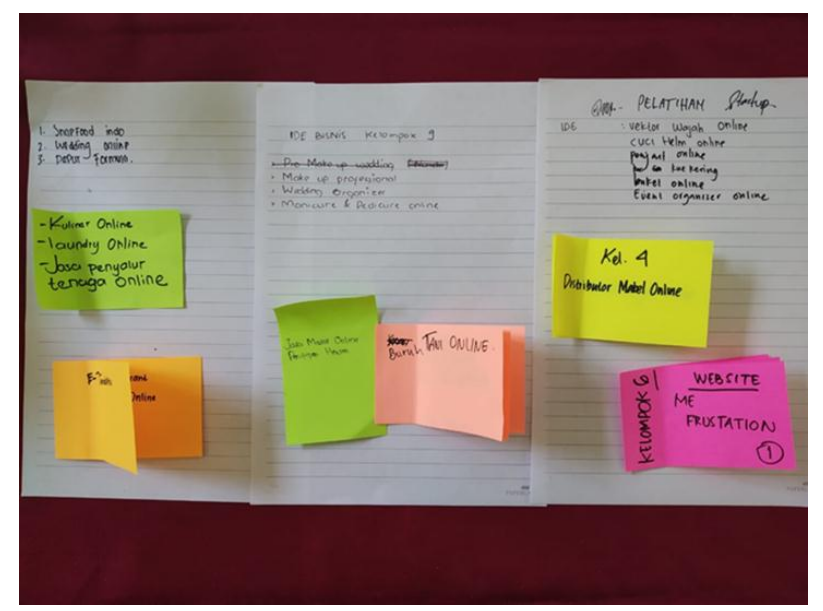

Gambar 4. Proses Menuangkan Ide Bisnis Tiap Kelompok

\section{Sprint Produk}

Pada sesi ini tiap kelompok mencoba menjawab pertanyaanpertanyaan kritis dari sebuah business plan dengan membuat desain, menciptakan prototype (bentukan awal, atau reka bentuk produk mulamula), dan juga menguji ide bisnis tersebut kepada user atau customer. Karena berupa simulasi yang menjadi customer adalah peserta itu sendiri yang berbeda kelompok.

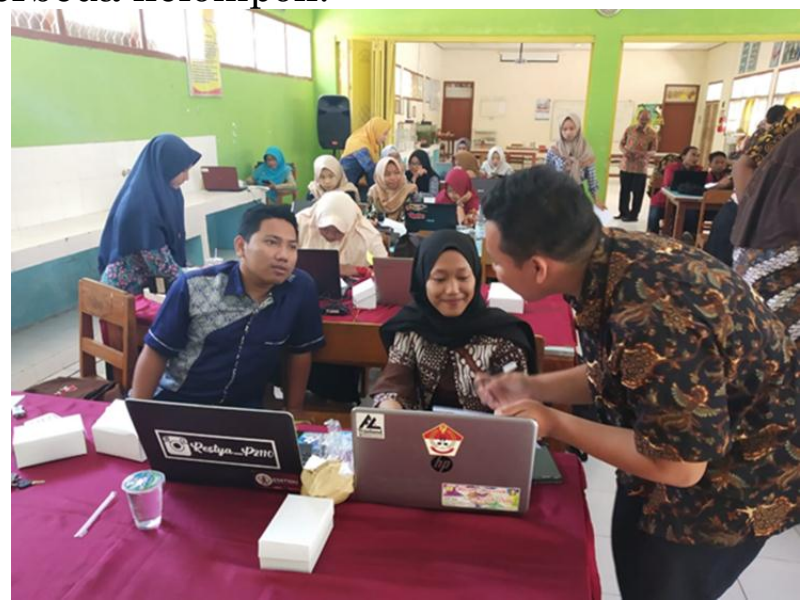

Gambar 5. Proses Sprint Produk

\section{Lean Camvas}

Pada sesi ini siswa dilatih untuk menjabarkan ide-ide dengan mengunakan meteode lean canvas. Siswa harus mengisi kotak-kotak kosong yang berisi tentang permsalahan utama yang terjadi lingkungan sekitar, solusi yang akan diberikan, keunikan produk yang akan dibuat, pemasukan yang bisa diperoleh darai pembuatan produk, pengeluaran yang dibutuhkan, dll. 


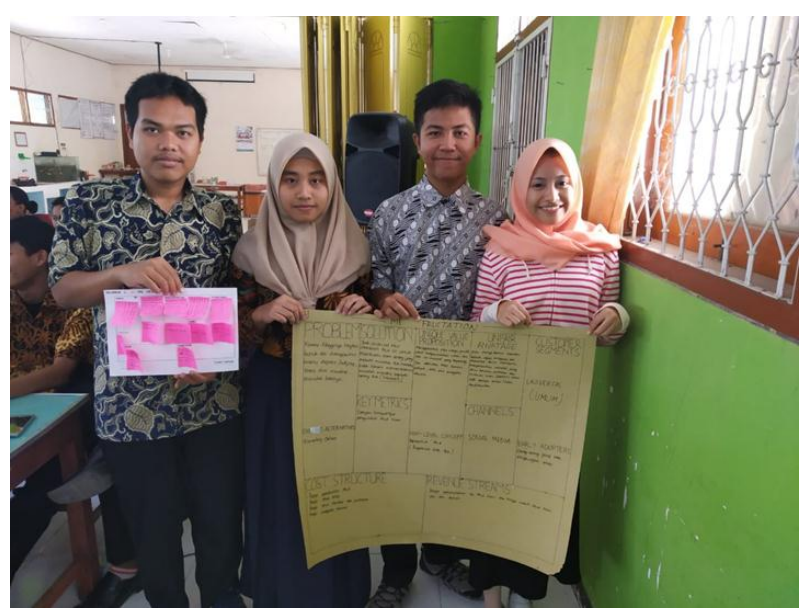

Gambar 6. Hasil Pembuatan Lean Canvas

\section{Struktur Organisai}

Siswa dilatih untuk membuat struktur organisasi dalam sebuah perusahaan startup. Satu kelompok ada lima siswa dimana tiap anggota akan berperan sebagai CEO (Chief Eksekutif Officer), CTO (Chief Technology Officer), CFO (Chief Finanacial Officer), CMO (Chief Marketing Officer) dan $\mathrm{COO}$ (Chief Operating Officer).

\section{Pitching}

Siswa dilatih untuk melakukan picthing di depan instruktur pelatih. Simulasi ini layaknya presentasi di depan investor agar tertarik terhadap ide dan produk yang akan dibuat. Instruktur juga akan memberikan masukan-masukan tentang apa yang menjadi kekurangankekurangan pada produk yang mau dibuat sehingga bisa menyempurnakan produknya. Pada sesi ini peserta akan diberi kesempatan 5 menit tiap kelompok untuk memepresentasikan hasil inovasi ide bisnis mereka di depan instruktur. Sebelum presentasi tiap kelompok juga diwajibkan juga untuk membuat logo perusahhan startup, karena logo merupakan hal penting juga dalam pembuatan startup.

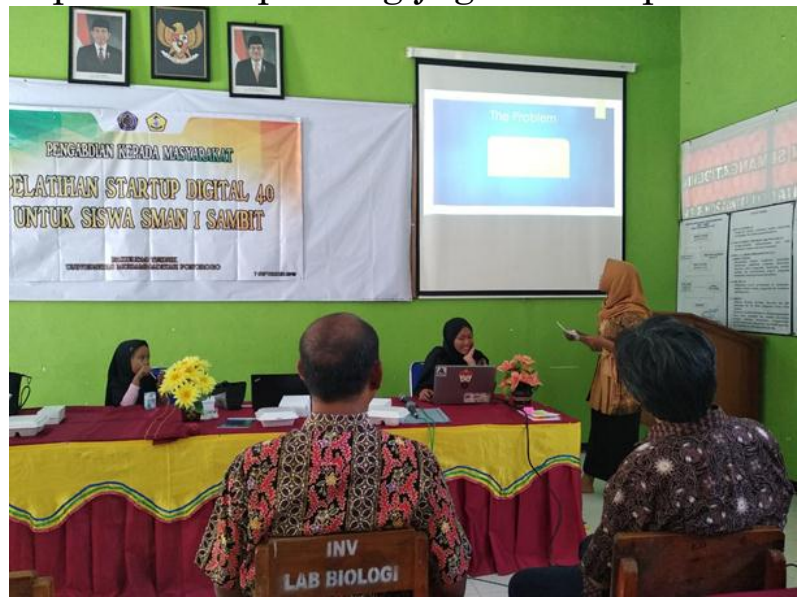

Gambar 7. Pitching di depan instruktur

\section{Prototyping}

Siswa dilatih untuk membuat desaign produk menggunakan aplikasi marvel. Marvel adalah perkakas online yang mengizinkan designer untuk membuat prototype dari proyek aplikasi ponsel dan situs. 

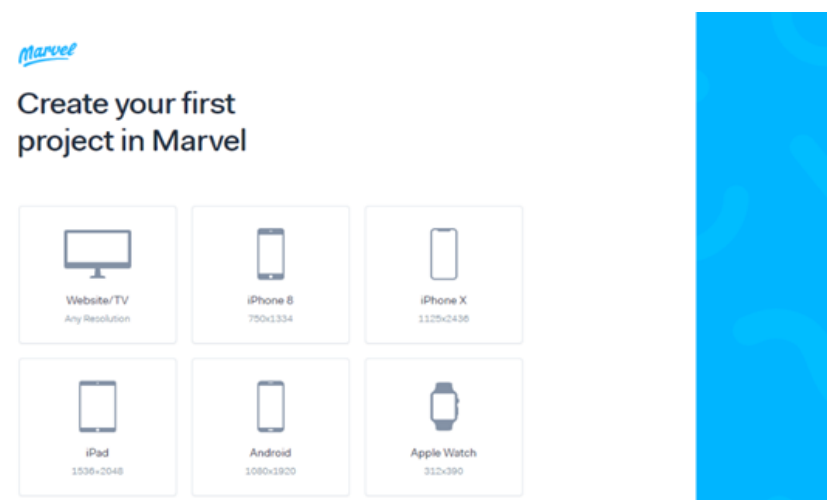

Gambar 8. Membuat Desain Prototype Produk

\section{Evaluasi Pelatihan}

Evaluasi Pelatihan adalah memilih tiga inovasi produk diantara sembilan kelompok yang paling berpotensi untuk dijadikan startup dan di ikutkan pada lomba yang levelnya lebih luas. Selanjutnya bimbingan pembuatan proposal akan diberikan setelah pelatihan berikutnya agar bisa mengikuti kompetisi di tingkat nassional. Adapun kelompok yang terpilih menurut instruktur adalah kelompok yang punya ide produk yang unik dan kreatif, antara lain idenya adalah : Sampah digital, me frustation dan market place untuk pertanian organik.

Peserta sangat antusias mengikuti pelatihan ini, karena peserta mempunyai pengalaman bagaimana langkah-langkah membuat sebuah startup walau itu hanya sebuah simulasi. Peserta tidak merasakan bosan karena pola pelatihan ini berpusat kepada peserta, yang aktif adalah peserta, instruktur hanya berperan sebagai pembimbing dan mengarahkan.

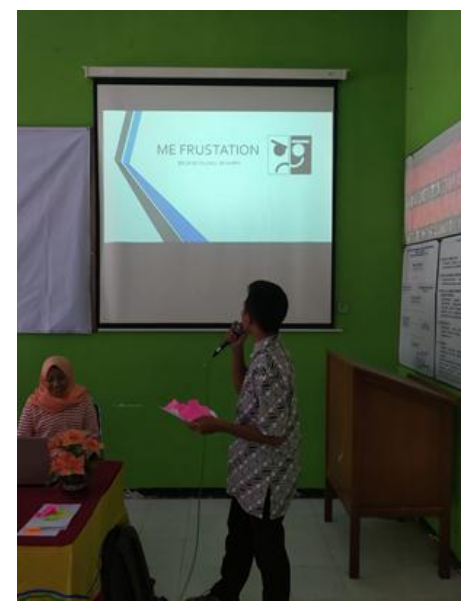

Gambar 9. Ide Produk me frustation yang terpilih dari tiga terbaik

\section{Evaluasi Pelaksanaan}

Hasil analisa pelaksanaan pengabdian akan disajikan berupa tabel data yang diperoleh dari hasil pengisian responden terhadap kuesioner yang diberikan. Pada kuesioner ini yang dijadikan target adalah peserta. Jumlah responden sebanyak 40 peserta, dan respon yang terkumpul sebanyak 39.

Dalam penghitungan hasil kuesioner yang didapat, penulis melakukan penghitungan metode Skala Likert. Skala Likert digunakan 
untuk menghitung persepsi, opini atau pendapat responden terhadap sebuah peristiwa berdasarkan pernyataan yang telah ditetapkan.

Setelah pernyataan yang diberikan kepada responden berhasil dilakukan, maka selanjutnya dilakukan pengolahan tiap butir kuesioner menggunakan skala likert. Perhitungan, hanya menggunakan metode skala likert.Bagian pengolahan data ini diambil dari hasil responden sebanyak 40 responden dan yang menigisi sebanyak 39 responden dengan dibagikan kuesioner secara online dengan menggunakan google form. Terdapat 10 pernyataan Kesimpulan.

Pengolahan Kuesioner Evaluasi Pelatihan Start Up Digital di SMAN 1 Sambit Terdapat 10 pernyataan dengan tiap pernyataan diisi oleh 39 responden. Maka keseluruhan bagian ini berhasil mengumpulkan 390 respon. Masing-masing yang menjawab KURANG SEKALI adalah 4 responden, yang menjawab KURANG adalah 11 responden, yang menjawab CUKUP adalah 109 responden, yang menjawab BAIK adalah 177 responden dan yang menjawab BAIK SEKALI adalah 88 responden.

Tabel 1. Pengolahan Kuesioner

\begin{tabular}{ccc}
\hline Skala Jawaban & T x Pn & Hasil \\
\hline Kurang Sekali & $4 \times 1$ & 4 \\
\hline Kurang & $11 \times 2$ & 22 \\
\hline Cukup & $109 \times 3$ & 327 \\
\hline Baik & $177 \times 4$ & 708 \\
\hline Baik Sekali & $88 \times 5$ & 440
\end{tabular}

Dengan $\mathrm{T}=$ Total jumlah responden yang memilih, $\mathrm{Pn}=$ Pilihan angka skor Likert. Dari hasil diatas maka total perhitungan skornya adalah:

$$
\begin{aligned}
& \text { Total }=4+22+327+708+440=1501 . \\
& \begin{aligned}
\text { Rumus Index } 100 \% & =\text { Total Skor } / \mathrm{Y} \times 100 \\
& =1501 / 1950 \times 100 \\
& =76 \%
\end{aligned}
\end{aligned}
$$

Berdasarkan dari hasil kuesioner yang diberikan kepada 39 responden dengan 10 pernyataan, didapatkan persentase $76 \%$ berada dalam skala interval baik. Artinya responden merespon dengan penilaian BAIK dengan adanya pelatihan startup digital di SMAN 1 Sambit

\section{SIMPULAN DAN SARAN}

Berdasarkan evaluasi pelatihan startup digital (1) peserta merespon dengan baik materi dan simulasi yang diberikan oleh instruktur pelatihan; (2) peserta mampu mengikuti dengan baik semua tahapan pelatihan dari cara memunculkan ide, sprint produk, mendesain bisnis dengan lean canvas, membuat prototype, logo perusahaan dan pitching di depan instruktur; dan (3) Sebagian besar peserta masih lemah dalam penguasaan coding yang dibutuhkan oleh dunia indsutri.

\section{UCAPAN TERIMA KASIH}

Terima kasih kepada SMAN 1 Sambit Ponorogo yang bersedia menjadi mitra dalam pelatihan startup digital 4.0 yang sudah menyediakan tempat, waktu dan anak didiknya untuk menjadi peserta. Tidak lupa juga ucapan terima kasih juga di haturkan kepada LPPM Universitas Muhammadiyah Ponorogo yang mendukung kegiatan dalam bentuk finansial dan semua 
pihak yang tidak bisa kami sebutkan satu persatu yang mendukung terlaksananya kegiatan ini.

\section{DAFTAR RUJUKAN}

Ameliah, R., Aziz, U. A., Ghofari, G., Putri, B. P., Agustin, R., Alfanisa, E. W., \& Praditya, M. D. (2018). Strategi Kewirausahaan Digital Sebuah Panduan Untuk UMKM, Startup dan E-Commerce. Seri Literasi Digital.

Cobantoro, A. F. (2017). Rekayasa Web Proxy Pada Komputer Mikro Untuk Keamanan Anak Dalam Berinternet. Seminar Nasional Dan Gelar Produk $2017,171$.

Cobantoro, A. F. (2018). Analisa QOS ( Quality Of Service) Pada Jaringan $R t-R W$. $4(1), 31-36$.

Digital, G. N. 1000 S. (2016). Bagaimana Tahapan 1000 startup digital.

Masykur, F., Prasetiyowati, F., Studi, P., Informatika, T., Ponorogo, U. M., \& Pi, R. (2016). Aplikasi Rumah Pintar ( Smart Home) Pengendali Peralatan. 3(1), $51-58$.

Ratna Wijayanti, L., Sutikno, T., \& Sukarnati, S. (2016). Konstribusi Pengetahuan Kewirausahaan, Pengalaman Prakerin, Dan Kreativitas Terhadap Kesiapan Berwirausaha. Jurnal Pendidikan - Teori, Penelitian, Dan Pengembangan, 1(7), 1364-1375. https://doi.org/10.17977/jp.v1i7.6565

Supratman, L. P. (2018). Penggunaan Media Sosial oleh Digital Native. Jurnal Ilmu Komunikasi, 15(1), 47-60. https://doi.org/10.24002/jik.v15i1.1243

Yohanna, L., \& Wijono, H. D. (2016). Intensi Berwirausaha Ditinjau Dari Kreativitas Dan Kecerdasan Emosional. In Sosio-E-Kons (Vol. 8). 